\title{
ENFERMEDAD DE MANO, PIE Y BOCA EN UN HOSPITAL DEL CALLAO, 2016
}

\author{
Milton José Max Rodríguez-Zúñiga ${ }^{1,3}$, Katherine Vértiz-Gárate ${ }^{2,3}$, Florencio Cortéz-Franco1, \\ Eberth Qujiano-Gomero'
}

\begin{abstract}
RESUMEN
La enfermedad de mano, pie y boca (EMPB) es una enfermedad exantemática viral, causada principalmente por Coxsackie A16, con una sintomatología típica consistente en fiebre; exantema pápulo-vesicular en manos, pies y genitales; y un enantema ulceroso en boca. En el verano del 2016 se presentó una diversidad de casos en un hospital del Callao en niños y adultos, con una sintomatología compatible con EMPB; el diagnóstico fue clínico, se aplicó terapia de soporte con resolución final de síntomas. En la última década se han presentado reportes en algunos países con una afectación atípica causada por el Coxsackie A6, produciendo lesiones más extensas y en adultos. Sin embargo, el diagnóstico sigue siendo clínico, solo necesitando confirmación virológica en casos atípicos o cuando el diagnóstico no es claro. La importancia de este reporte radica en describir los casos del Callao ocurridos en el verano del 2016, para servir de apoyo a los profesionales de la salud en el diagnóstico y manejo de pacientes con similar sintomatología.
\end{abstract}

Palabras clave: Enfermedad de Mano, Pie y Boca; Niño; Adulto; Infecciones por Coxsackievirus, Enterovirus; Exantema (fuente: DeCS BIREME).

\section{HAND, FOOT, AND MOUTH DISEASE IN A HOSPITAL IN CALLAO IN 2016}

\begin{abstract}
Hand, foot, and mouth disease (HFMD) is an exanthematous viral disease caused mainly by Coxsackie $A 16$ with a typical symptomatology of fever, papulovesicular rash on the hands, feet, and genitals, and an ulcerous enanthem in the mouth. In the summer of 2016, a variety of cases presented at a hospital in Callao in children and adults with a symptomatology consistent with HFMD. A clinical diagnosis was made, and support therapy was applied, resulting in the resolution of symptoms. In the last decade, reports have emerged in some countries of an atypical involvement caused by Coxsackie A6, producing lesions that are more widely distributed in adults. However, the diagnosis remains clinical, only requiring virological confirmation in atypical cases or when the diagnosis is unclear. The importance of this report stems from its description of the cases in Callao that occurred in the summer of 2016 and serve as an example for health professionals in the diagnosis and management of patients with similar symptomatology.
\end{abstract}

Keywords: Hand, foot and mouth disease; Child; Adult; Coxsackievirus Infections, Enterovirus; Exanthema (source: MeSH NLM).

\section{INTRODUCCIÓN}

La enfermedad de mano, pie y boca (EMPB) es una enfermedad viral frecuente durante los meses de verano, en niños de 0 a 4 años; sin embargo, se han descrito en la literatura casos en niños mayores, adolescentes y adultos ${ }^{(1,2)}$. Clásicamente, inicia con malestar general y odinofagia, seguidos de fiebre, dolor bucal, dolor abdominal y síntomas respiratorios. La erupción mucocutánea típica se caracteriza por un enantema consistente en vesículas o úlceras en mucosa bucal, cubiertas por una pseudomembrana amarillenta, rodeadas por un halo eritematoso. El exantema aparece en manos, pies, glúteos y región del pañal, inicia de forma máculo-papular y evolucionan rápidamente a vesículas grises de 3 a $7 \mathrm{~mm}$ rodeadas de un halo rojo de forma

\footnotetext{
Servicio de Dermatología del Hospital Nacional Daniel Alcides Carrión, Callao, Perú.

Servicio de Pediatría del Hospital San Bartolomé, Lima, Perú.

Universidad Nacional Mayor de San Marcos, Lima, Perú.

Recibido: 08/09/2016 Aprobado: 25/01/2017 En línea: 23/03/2017
}

Citar como: Rodríguez-Zúñiga MJM, Vértiz-Gárate K, Córtez-Franco F, Qujiano-Gomero E. Enfermedad de mano, pie y boca en un hospital del Callao, 2016. Rev Peru Med Exp Salud Publica. 2017;34(1):132-8. doi: 10.17843/rpmesp.2017.341.2710 
oval, lineal o en media luna; se disponen en las caras laterales y dorsales de los dedos de manos y pies, en la región periungueal y en palmas y plantas. Las vesículas hacen costra y desaparecen en 7 a 10 días ${ }^{(3,4)}$.

Se produce principalmente por la infección de dos virus ARN del género Enterovirus Coxsackie A 16 (CA16) y Enterovirus 71 (E71) ${ }^{(5)}$. Sin embargo, desde el 2008 se vienen reportando epidemias en Asia, Estados Unidos y Europa, de la variedad de CA6, que produce lesiones más extensas y vesiculares, con localizaciones inusuales, conocido como formas atípicas ${ }^{(4,6,7)}$.

En el Perú, son escasos los reportes de brotes de EMPB en niños y adultos en los últimos años ${ }^{(8)}$. Es importante para la salud pública estar al tanto de los brotes de las enfermedades emergentes y reemergentes como EMPB, que han venido sucediendo a nivel mundial, y que incluyen formas severas y fulminantes que aún no han sido reportadas en el Perú ${ }^{(9)}$. Así mismo, es necesario que los profesionales de la salud reconozcan las formas típicas de EMPB: los síntomas prodrómicos; los síntomas sistémicos que preceden un enantema oral y exantema pápulo vesicular en manos y pies, y que finalmente terminan en descamación acral u onicomadesis. De esta manera se evitarían exploraciones innecesarias, que pueden significar seguridad y ahorro para los pacientes y el estado ${ }^{(10)}$.

Se realiza el presente reporte de los casos presentados durante un brote en el verano del 2016 en un Hospital Nacional Daniel Alcides Carrión (HNDAC) del Callao, con el objetivo de alertar a los médicos, revisar el tema, y facilitar su diagnóstico en los pacientes.

\section{REPORTE DE CASOS}

Seis pacientes acudieron al Servicio de Dermatología del HNDAC durante el verano del 2016, con una sintomatología compatible con EMPB (Tabla 1).

\section{CASO 1}

Varón de 28 años que presentó fiebre, odinofagia y malestar general, y que posteriormente desarrolla un exantema máculo-papular doloroso palmoplantar, y un enantema vesicular en lengua. El examen de reagina plasmática rápida (RPR) fue negativo. El cuadro se resolvió a la semana con analgésicos (Figura 1).

\section{CASO 2}

Niña de 5 años, que tras presentar fiebre y odinofagia desarrolla un exantema pápulo-vesicular eritematoso indoloro en región lateral de los dedos de las manos, pies y en la región perianal. Se le indica tratamiento de soporte, con resolución de las lesiones a los pocos días (Figura 2).

\section{CASO 3}

Mujer de 23 años, que presenta cuadro de malestar general, asociado a fiebre y odinofagia. Cuatro días después desarrolla súbitamente exantema pápulovesicular doloroso en cara lateral, dorso, palmas y plantas de manos y pies, con enantema vesicular en labios y carrillos. El hemograma resultó sin alteraciones y el RPR negativo. El cuadro se resolvió luego de dos semanas con antipiréticos y analgésicos (Figura 3).

Tabla 1. Descripción de los pacientes incluidos en la serie de casos

\begin{tabular}{|c|c|c|c|c|c|c|c|}
\hline Caso & $\begin{array}{c}\text { Edad } \\
\text { (años) y } \\
\text { sexo }\end{array}$ & $\begin{array}{l}\text { Tiempo } \\
\text { (días) }\end{array}$ & Síntomas & Lesiones en piel & Distribución & $\begin{array}{c}\text { Sintomatología } \\
\text { de lesión } \\
\text { cutánea }\end{array}$ & Úlcera oral \\
\hline 1 & $28, \mathrm{M}$ & 1 & $\begin{array}{c}\text { Fiebre, odinofagia, } \\
\text { malestar general }\end{array}$ & Pápulo macular & Palmas, plantas. & $\begin{array}{l}\text { Dolor a la } \\
\text { presión }\end{array}$ & Sí (lengua) \\
\hline 2 & $5, F$ & 2 & Fiebre, odinofagia & Pápulo macular & $\begin{array}{c}\text { Palmas, plantas y } \\
\text { perianal }\end{array}$ & Sin dolor & No \\
\hline 3 & $23, \mathrm{~F}$ & 4 & $\begin{array}{l}\text { Fiebre, malestar } \\
\text { general, odinofagia }\end{array}$ & Pápulo vesicular & Manos y pies & Con dolor & $\begin{array}{l}\text { Sí (mucosa } \\
\text { labios y } \\
\text { carrillos) }\end{array}$ \\
\hline 4 & $8, M$ & 3 & Fiebre, odinofagia & Pápulo macular & Palmas y plantas & $\begin{array}{l}\text { Dolor a la } \\
\text { presión }\end{array}$ & No \\
\hline 5 & $26, \mathrm{M}$ & 4 & Fiebre, odinofagia & Pápulo macular & Plantas y palmas & $\begin{array}{c}\text { Dolor a la } \\
\text { presión }\end{array}$ & No \\
\hline 6 & 7, M & 45 & $\begin{array}{c}\text { Fiebre y malestar } \\
\text { general, odinofagia } \\
\text { que se auto resuelve } \\
\text { a la semana }\end{array}$ & Onicomadesis & $\begin{array}{l}\text { Dedo índice de } \\
\text { mano izquierda y } \\
\text { primer dedo pie } \\
\text { izquierdo }\end{array}$ & Sin dolor & No \\
\hline
\end{tabular}



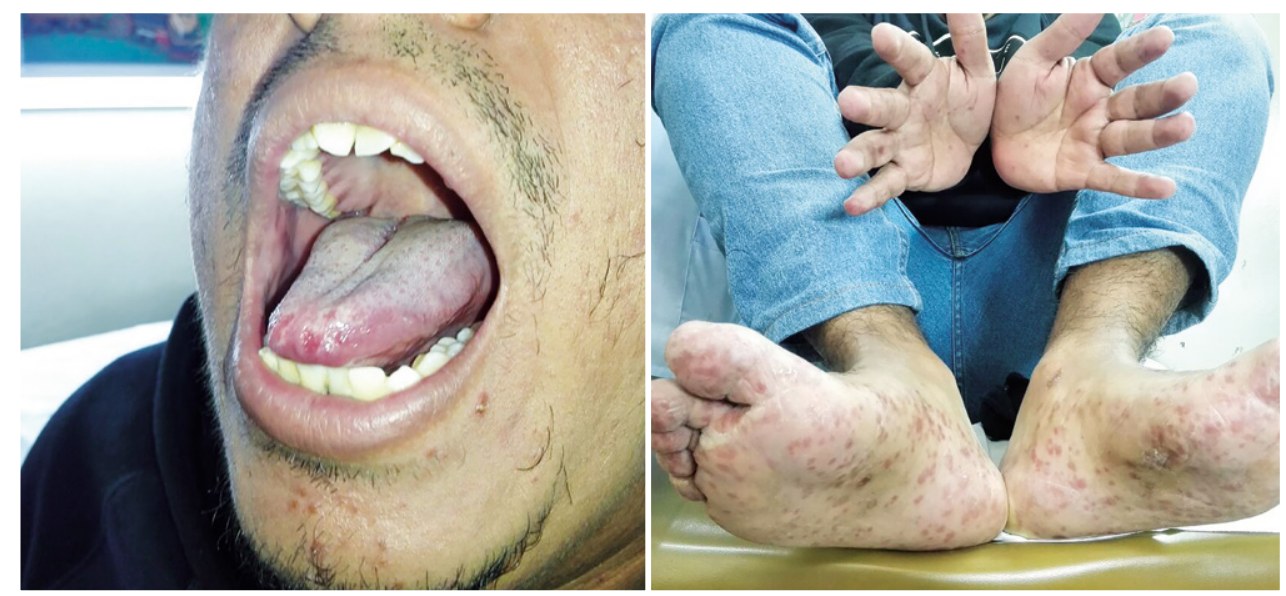

Figura 1. Exantema pápulo-macular en palmas y plantas, con úlceras en lengua. Prueba no treponémica negativo (caso 1)

\section{CASO 4}

Niño de 8 años que luego de 3 días de fiebre y malestar general, presenta exantema máculo-papular doloroso a la palpación en el borde lateral, palmas y plantas de manos y pies, sin enantema. Los síntomas resuelven a los pocos días con tratamiento de soporte (Figura 4).

\section{CASO 5}

Varón de 26 años que luego de 4 días de fiebre y odinofagia presenta erupción máculo-papular dolorosa a la palpación en palmas y plantas de manos y pies. El hemograma resultó sin alteraciones, y el RPR negativo. Los síntomas resuelven con tratamiento de soporte (Figura 5).

\section{CASO 6}

Niño de 7 años que consulta por presentar desprendimiento de la parte proximal de las uñas del segundo y primer dedo de mano y pie izquierdos, respectivamente (onicomadesis). Refirió que semanas atrás presentó un cuadro febril, con malestar general y odinofagia, sin evocar exantema ni enantema. El cuadro se autorresolvió sin complicaciones (Figura 6).

\section{DISCUSIÓN}

La EMPB descrita inicialmente por Robinson, es una virosis común de la infancia predominantemente en menores de 10 años, y raramente visto en adultos a consecuencia de la inmunidad cruzada con otros
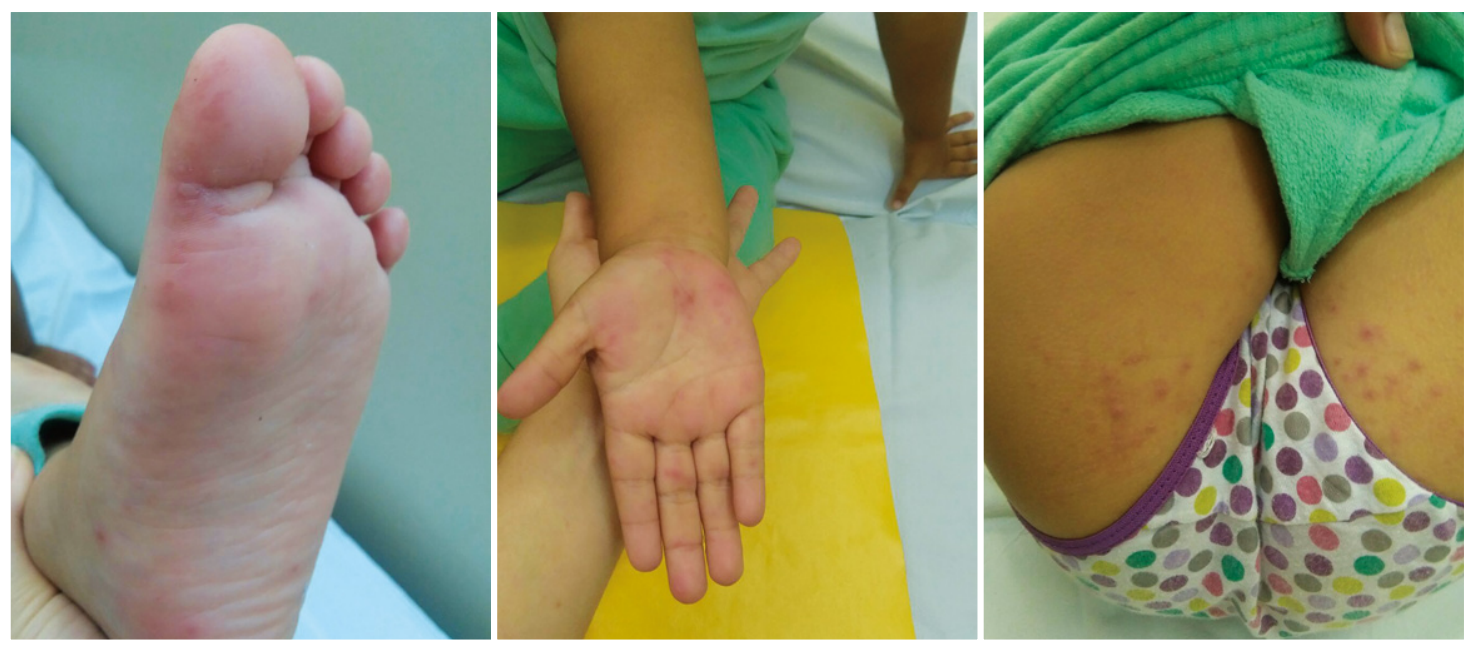

Figura 2. Pápulas y máculas eritematosas en palmas, plantas y región perianal (caso 2). 


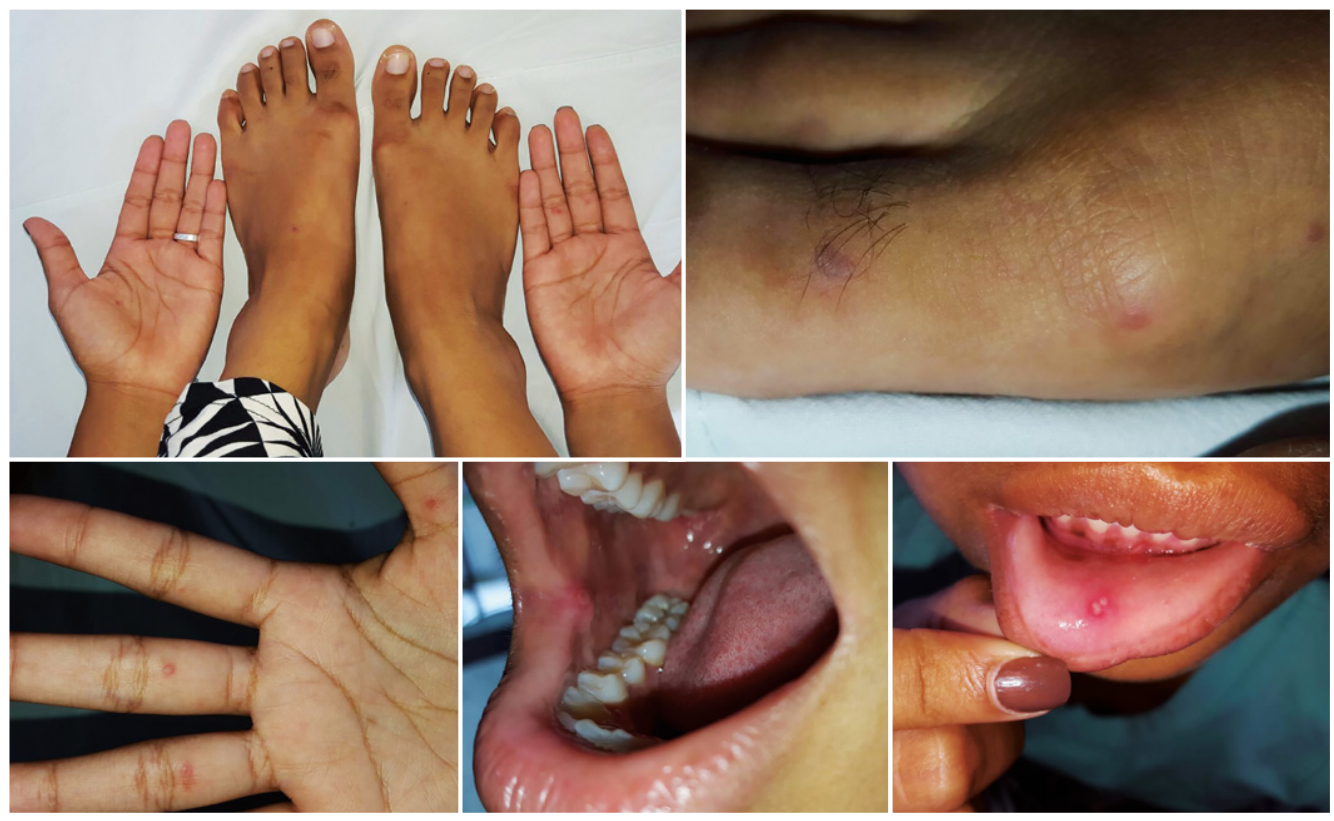

Figura 3. Pápulas y vesículas eritematosas en pies y manos con enantema ulceroso en labios (caso 3)

enterovirus y memoria inmunológica ${ }^{(2)}$. En su origen se describió que era causado comúnmente por el CA16 en temporadas de verano, y suele presentarse en forma de pequeños brotes epidémicos que generalmente quedan limitados a las instituciones escolares, guarderías o de preescolar, con formas típicas descritas anteriormente ${ }^{(11)}$.

En mayo de 2016, la Dirección de Salud del Callao lanzó una alerta epidemiológica en el que daba cuenta de 21 casos en Lima y seis en Callao, de niños de instituciones educativas con EMPB ${ }^{(8)}$. Sin embargo, en nuestra serie la mitad fueron adultos, similar a lo que se ha venido reportando desde el 2008 en asociación a infección por CA6, causante de brotes más severos y atípicos en niños y adultos ${ }^{(1)}$.

Debido a las formas atípicas, severas y extensas reportadas en Asia, Europa y Norteamérica, en el 2012 el Centro para

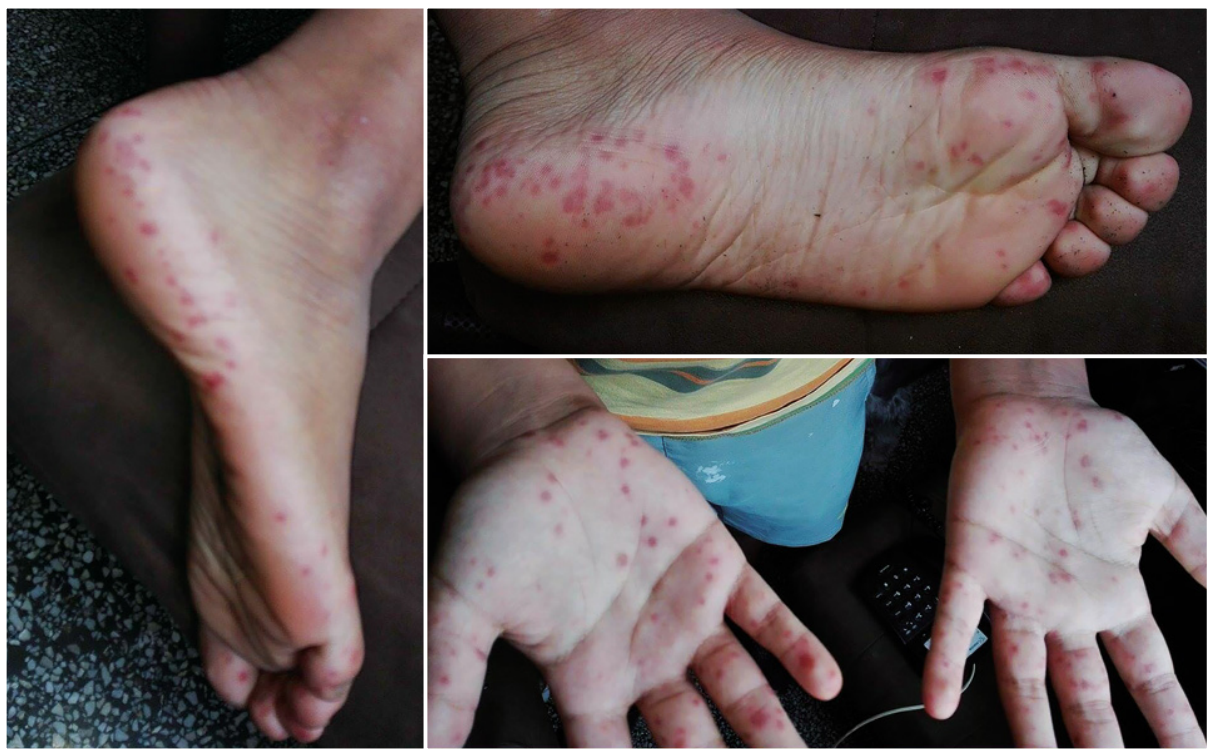

Figura 4. Exantema papular y acular en palmas y plantas. No enantema (caso 4) 

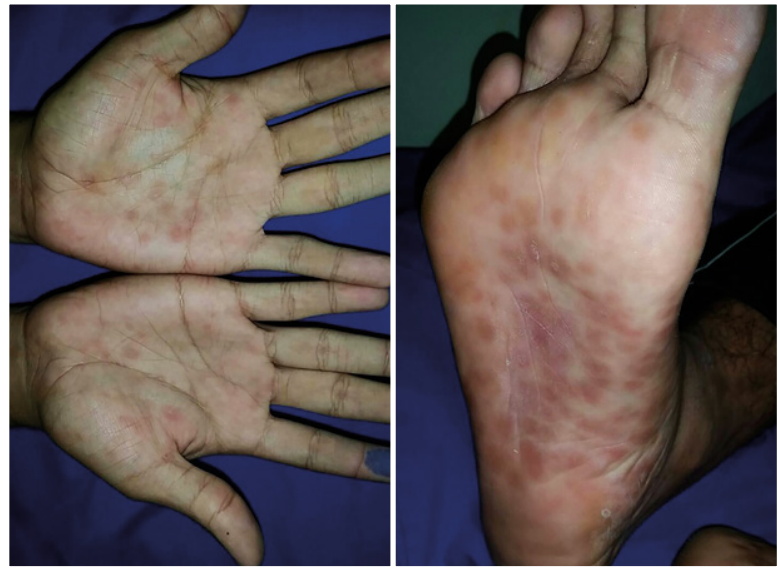

Figura 5. Exantema pápulo-macular en palmas y plantas. No enantema. Prueba no treponémica negativa (caso 5)

el Control de Enfermedades de Estados Unidos estableció criterios diagnósticos a partir de los casos reportados ${ }^{(12)}$. Esta distribución extensa de las lesiones se asocia a un serotipo CA6 y a factores de riesgo como edad menor de 3 años y dermatitis atópica ${ }^{(2,13)}$. Dichas presentaciones se conocen como las formas atípicas de EMPB, y difieren en que afectan el área perioral, extremidades y torso, adicional a las manifestaciones clásicas del EMPB, con un exantema eritematoso papular que ocupan más del $10 \%$ de superficie corporal total (SCT), y menor compromiso oral ${ }^{(4,14)}$. Cuatro morfologías distintas caracterizan este exantema atípico ${ }^{(4)}$ :

a). Erupción vesicular y erosiva generalizada, con una extensión mayor al $5 \%$ de SCT, con predilección perioral, acral y glútea, que continúa al exantema inicial. Las ampollas se ven más comúnmente en menores de un año. b). Eccema Coxsackie, frecuente en niños con dermatitis atópica. Las vesículas y erosiones se observan en las zonas de flexuras, como fosa antecubital y poplítea. c). Exantema petequial y purpúrico, frecuente en mayores de 5 años de edad, generalmente en zonas acrales. d). Erupción tipo Gianotti-Crosti, con vesículas y erosiones papulares en localización acro-facial con preservación del tronco.

En nuestra serie de pacientes, todos iniciaron el cuadro con síntomas sistémicos, como fiebre, malestar general y/o odinofagia. Luego, niños y adultos presentaron un exantema que en algunos fue máculo-papular (casos 1 , 2,4 y 5), y en otro pápulo-vesicular (caso 3), localizado en zona acral (manos, pies, palmas y plantas) y en una niña en zona perianal, en la mayoría dolorosas, asociado al enantema vesicular en boca (casos 1 y 3 ). Un estudio ${ }^{(5)}$ reportó una epidemia de 376 niños entre 6 a 36 meses de edad, con cuadro clínico similar de fiebre $(75 \%)$, seguido de erupción vesicular en palmas $(71 \%)$, plantas $(68 \%)$, estomatitis erosiva $(64 \%)$ y

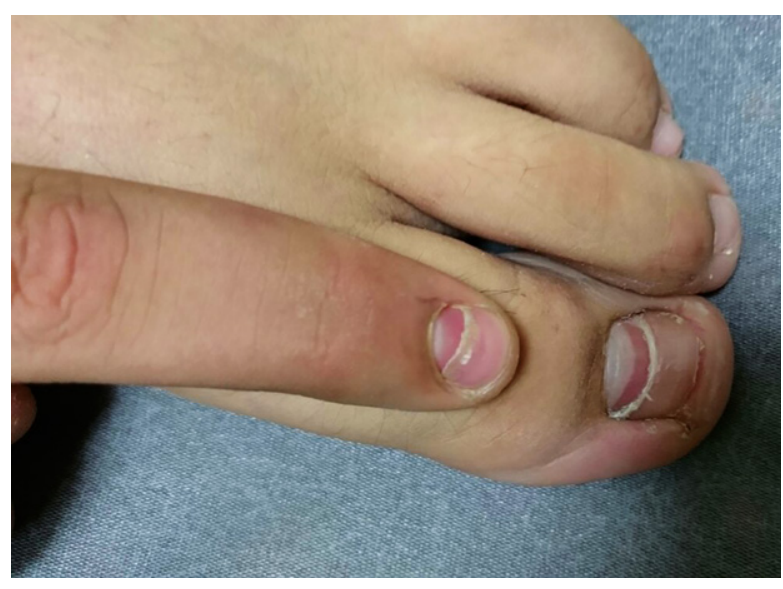

Figura 6. Desprendimiento completo y espontaneo de la uña (onicomadesis) (caso 6)

posterior onicomadesis (46\%), aislándose el CA16 en 5 pacientes. Sin embargo, no describió pacientes adolescentes ni adultos.

En todos los casos, el compromiso fue menor al $10 \%$ de SCT, y tampoco comprometían la región perioral ni zonas de flexuras. De esta forma, creemos que los casos ocurridos en nuestro hospital pertenecen a cuadros típicos asociados al CA16, a pesar de presentarse también en adultos. Mientras tanto, otras revisiones dan cuenta de que las formas en adultos se asocian al CA6 ${ }^{(1)}$. Se han descrito cambios en las uñas y en la piel luego de la etapa aguda de la enfermedad: descamación de las plantas y palmas después de unas semanas; onicomadesis 3 a 8 semanas después del diagnóstico (media de 52 días), y líneas de Beau ${ }^{(15)}$. Estos cambios ungueales ocurren debido a un arresto temporal de la actividad de la matriz ungueal. Así, el caso 6 presentó onicomadesis a los 45 días de haber presentado un cuadro febril autorresolutivo.

La transmisión es de persona a persona vía oral-oral o fecal-oral. Luego de su distribución en la orofaringe y en el tracto gastrointestinal, el virus se dispersa a los ganglios linfáticos locales, produciendo una viremia la cual se manifiesta en síntomas generales ${ }^{(2)}$.

El diagnóstico diferencial es importante para evitar exploraciones innecesarias. Para el enantema se debe considerar gigivoestomatitis herpética y estomatitis aftosa. El exantema pápulo vesicular típico se diferencia de las del herpes simple por su disposición en racimos, y de la varicela, porque duran más tiempo y siempre costrifican. Además, aquellas presentan degeneración balonante en el test de Tzanck, que no se da en la EMPB. Así mismo, considerar el eccema herpético, impétigo buloso, 
síndrome de Gianotti-Crosti, urticaria multiforme, vasculitis leucocitoclástica, púrpura en guante y calcetín, entre otras, como diferenciales de las formas atípicas ${ }^{(3,4,16)}$.

El diagnóstico es clínico y generalmente los estudios de laboratorio no son necesarios, ya que la mayoría resultan normales, solo requiriendo el análisis viral con reacción en cadena de polimerasa (PCR) en las presentaciones atípicas, en muestras obtenidas de biopsia, conjuntiva, orofaringe, piel perianal, sangre y heces ${ }^{(13,17)}$. En nuestra serie, el diagnóstico se basó en la sintomatología y distribución de lesiones, excluyendo otras patologías como secundarismo sifilítico en casos de adultos. El pronóstico es bueno, en su mayoría tiende a la resolución espontánea, tal como sucedió en todos los casos de la presente revisión.

\section{CONCLUSIÓN}

Se presentan seis casos de EMPB que ocurrieron en el verano del 2016 en niños y adultos que fueron tratados en el HNDAC. Los pacientes presentaron síntomas típicos, consistentes en fiebre y malestar general, exantema pápulo-vesicular en manos y pies, enantema ulcerativo, y posterior onicomadesis. Todos los casos tuvieron un diagnóstico clínico, exámenes auxiliares dentro de los rangos normales, y el tratamiento consistió en medidas de soporte con un buen pronóstico. Es importante reconocer los casos de EMPB tanto típicos como atípicos, para brindar tranquilidad a los pacientes y evitar medidas diagnósticas y terapéuticas invasivas e innecesarias que pueden generar un riesgo o gasto para el paciente o el estado.

Contribuciones de autoría: MJMRZ, KVG, FCF y EQG han participado en concepción y diseño del artículo, recolección y obtención de los datos, redacción y revisión crítica del artículo y en la aprobaron la versión final.

Fuente de financiamiento: el presente trabajo ha sido autofinanciado.

Conflictos de interés: los autores declaran no tener ningún conflicto de interés

\section{REFERENCIAS BIBLIOGRÁFICAS}

1. Downing C, Ramirez-Fort MK, Doan HQ, Benoist F, Oberste MS, Khan F, et al. Coxsackievirus A6 associated hand, foot and mouth disease in adults: clinical presentation and review of the literature. J Clin Virol.2014;60(4):3816. doi: 10.1016/j.jcv.2014.04.023.

2. Ventarola D, Bordone L, Silverberg N. Update on hand-foot-andmouth disease. Clin Dermatol. 2015;33(3):340-6. doi: 10.1016/j. clindermatol.2014.12.011

3. Hubiche T, Schuffenecker I, Boralevi F, Leaute-Labreze C, Bornebusch L, Chiaverini C, et al. Dermatological spectrum of hand, foot and mouth disease from classical to generalized exanthema. Pediatr Infect Dis J. 2014;33(4):e92-8. doi: 10.1097/ INF.0000000000000120.

4. Mathes EF, Oza V, Frieden IJ, Cordoro KM, Yagi S, Howard R, et al. "Eczema coxsackium" and unusual cutaneous findings in an enterovirus outbreak. Pediatrics. 2013;132(1):e149-57. doi: 10.1542/peds.2012-3175.
5. Navarro Moreno E, Almagro Lopez D, Jaldo Jimenez R, Del Moral Campana MC, Arbol Fernandez G, Perez Ruiz $\mathrm{M}$, et al. Brote de enfermedad bocamano-pie y onicomadesis causado por el virus Coxsackie A16, Granada. An Pediatr (Barc). 2015;82(4):235-41. doi: $10.1016 /$ j.anpedi.2014.05.015

6. Second J, Velter C, Cales S, Truchetet F, Lipsker D, Cribier B. Clinicopathologic analysis of atypical hand, foot, and mouth disease in adult patients. J Am Acad Dermatol. 2016. pii: S0190-9622(16)30996-3. doi: 10.1016/j.jaad.2016.10.022.

7. Lott JP, Liu K, Landry ML, Nix WA, Oberste MS, Bolognia J, et al. Atypical hand-foot-and-mouth disease associated with coxsackievirus A6 infection. J Am Acad Dermatol. 2013;69(5):736-41. doi: 10.1016/j. jaad.2013.07.024

8. Direccion Regional de Salud de Callao. Recomendaciones frente al virus Coxsackie. Alerta Epidemiológica 032016. Mayo 2016. Disponible en: http:// www.diresacallao.gob.pe/wdiresa/ documentos/boletin/epidemiologia/ alertas/FILE0002552016.pdf

9. Cabezas-Sanchez C. Enfermedades infecciosas emergentes reemergentes y sus determinantes. Rev Peru Med Exp Salud Publica. 2015;32(1):7-8.

10. Cavero-Guardamino J. Enfermedad de mano, pie y boca. Folia Dermatológica Peruana. 1997;8(2).

11. Direccion Regional de Salud de Callao. Oficina de Epidemiologia. Enfermedad de mano-pie-boca (Enterovirus Coxsackie A16) (SE) No17. Boletín Epidemiológico Abril 2016. Disponible en: http://www.diresacallao.gob. pe/wdiresa/documentos/boletin/ epidemiologia/FILE0001892016.pdf

12. Centers for Disease C, Prevention. Notes from the field: severe hand, foot, and mouth disease associated with coxsackievirus A6 - Alabama, Connecticut, California, and Nevada, November 2011-February 2012. MMWR Morb Mortal Wkly Rep. 2012;61(12):213-4. 
13. Feder HM, Jr., Bennett N, Modlin JF. Atypical hand, foot, and mouth disease: a vesiculobullous eruption caused by Coxsackie virus A6. Lancet Infect Dis. 2014;14(1):83-6. doi: 10.1016/S1473-3099(13)70264-0.

14. Sinclair C, Gaunt E, Simmonds P, Broomfield D, Nwafor N, Wellington $\mathrm{L}$, et al. Atypical hand, foot, and mouth disease associated with coxsackievirus A6 infection, Edinburgh, United Kingdom, January to February 2014.
Euro Surveill. 2014;19(12):20745.

15. Redondo Granado MJ, Torres Hinojal MC, Izquierdo Lopez B. Brote de onicomadesis posvírica en Valladolid. An Pediatr (Barc). 2009;71(5):436-9. doi: 10.1016/j.anpedi.2009.07.033

16. Scott LA, Stone MS. Viral exanthems. Dermatol Online J. 2003;9(3):4.

17. Buttery VW, Kenyon C, Grunewald S, Oberste MS, Nix WA. Atypical Presentations of Hand, Foot, and Mouth Disease Caused by Coxsackievirus A6--Minnesota, 2014. MMWR Morb Mortal Wkly Rep. 2015;64(29):805.

Correspondencia: Milton José Max Rodríguez Zúñiga. Dirección: Av. Prolongación Iquitos 1570, Dpto. 905. Lince. Perú

Teléfono: (511) 950111539

Correo:mijomax@gmail.com

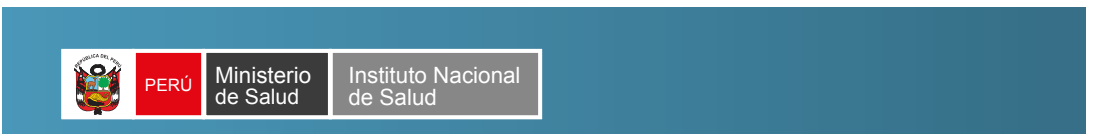

\section{Inclusión social en salud: acercando el diagnóstico de dengue a las poblaciones afectadas}

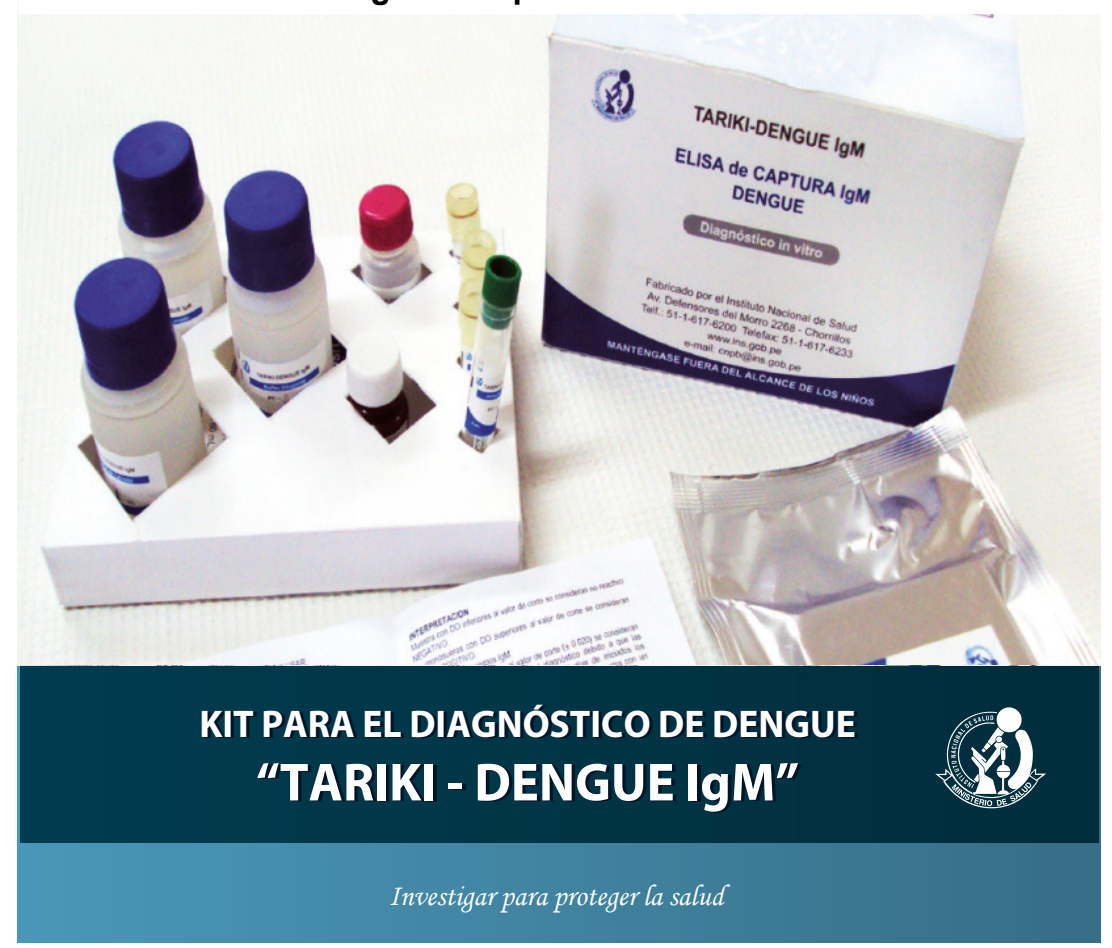

